\title{
Management of an Aberrant Mandibular Buccal Frenum - A Case
}

\section{Report}

\author{
Anahita $\mathbf{P}^{1 *}$, Thomas $\mathrm{B}^{2}$ and Amitha $\mathrm{R}^{3}$ \\ ${ }^{1}$ Department of Periodontics, Kaloji Narayana Rao University of Health Sciences, India \\ ${ }^{2}$ Department of Periodontics, NITTE University, India
}

*Corresponding author: Anahita Punj, Senior Lecturer, Department of Periodontics,

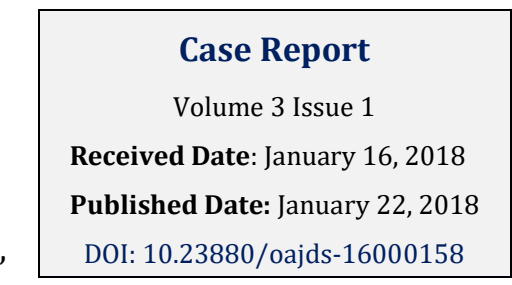

Army College of Dental Sciences, Jai Jawahar Nagar, Chennapur-CRPF Road, Secunderabad, Telangana- 500087, India, anahitapunj@gmail.com

\begin{abstract}
Aberrant frenal attachments pose a concern for the patient as it can interfere with aesthetics, plaque control and result in mucogingival deformities. This calls for the management of these anatomical structures by frenectomy or frenotomy depending upon its attachment and location. Labial and lingual frenectomies/frenotomies are routinely performed periodontal plastic procedures. In few cases, the presence of an aberrant buccal frenum of the mandibular arch maycall for a similar approach for its management to prevent further gingival recession and maintain gingival health.
\end{abstract}

Keywords: Buccal frenum; Frenotomy; Gingival recession

\section{Introduction}

Frenum is defined as a band or fold of mucosal membrane which encloses muscle fibres and attaches the lips and cheeks to the alveolar mucosa and/or gingiva and underlying periosteum. The frenum limits the movements of lips and cheeks $[1,2]$. The frenum can be classified as mucosal, when the frenal fibres are attached up to mucogingival junction; gingival, when fibres are inserted within attached gingiva; papillary, when fibres are extended into interdental papilla and papilla penetrating, when the fibres cross the alveolar process and extend up to the palatine papilla [3]. A high labial frenum attachment is a normal finding in almost $85 \%$ of infants, which may decrease with normal development. If it fails to do so, it may persist as an aberrant frenal attachment [4]. The management of aberrant frenal attachments involves two procedures frenectomy and frenotomy, which can be carried out using surgical blade, electrocautery or more popularly a soft tissue laser.
Frenectomy is carried out to remove the whole frenum along with its attachment to the alveolar bone. Frenotomy involves removal and relocation of the frenum to a more apical position. These procedures can be carried out separately or in conjunction with other periodontal plastic procedures $[1,2]$.

\section{Case Report}

A 44 year old male patient reported to the department of periodontics, with the complaint of bleeding of gums since 1 year and mild sensitivity on drinking cold water in lower back teeth since 6 months. The patient had no relevant dental or medical history. On examination the patient had bleeding on probing and pocket depth of $6 \mathrm{~mm}$ with respect to mandibular right molars, an aberrant buccal frenum attachment and Millers [5] class I gingival recession with recession depth of 3-4 $\mathrm{mm}$ (Figure 1) in relation to mandibular right first premolar. 


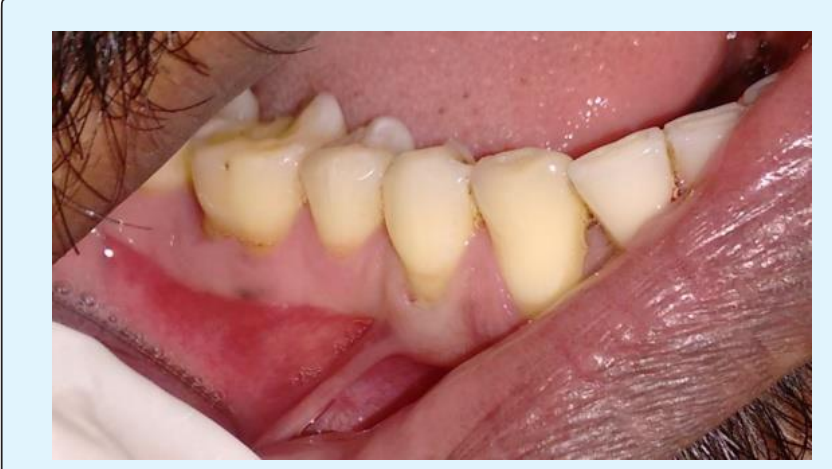

Figure 1: Pre-operative view showing buccal frenum.

On examination of intraoral periapical radiograph (IOPA) revealed interdental bone loss between mandibular right molars. The patient underwent full mouth scaling and root planning and was prescribed $0.2 \%$ chlorhexidine mouthwash to be used twice daily 20 minutes after brushing with a soft bristled toothbrush and use of desentizing toothpaste over mandibular right first premolar. After 3 weeks, the pocket depth of $5 \mathrm{~mm}$ was persisting and open flap debridement of mandibular right molars was planned along with frenotomy of the buccal frenum in relation to mandibular right first premolar to prevent further gingival recession of the same tooth. The two procedures were planned together to avoid multiple appointments. The area of interest was anaesthetized using 2\% lignocaine with 1: 80000 adrenaline. Open flap debridement with respect to mandibular right molars was done and the flap was sutured using 3-0 silk sutures. Next, as the tissues were already anesthetized, the buccal frenotomy was performed in the following manner. The buccal frenum was made taut by gently averting and pulling out the lips and a small incision was made surgically with number 15 Bard Parker bladeto sever the attached fibres, close to its attachment (Figure 2).

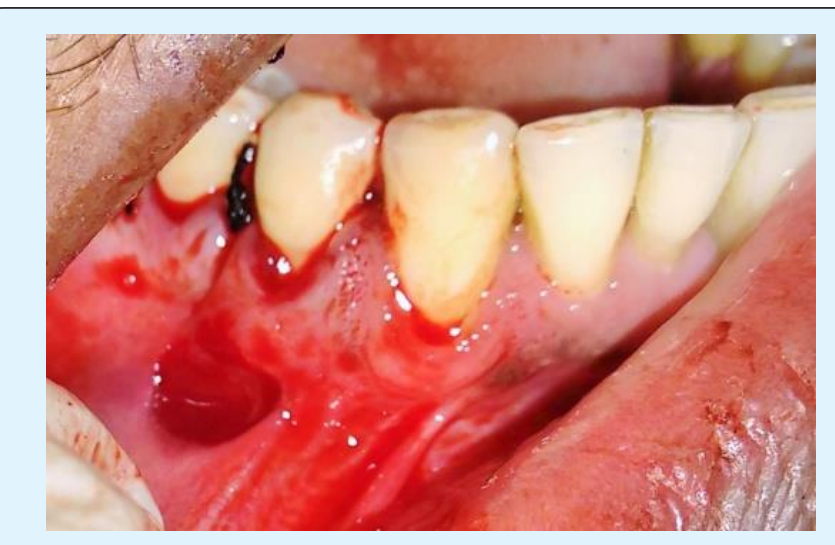

Figure 2: Intraoperative view during buccal frenotomy.
Later, the area was sutured without tension using 3-0 silk suture to maintain its apical position (Figure 3).

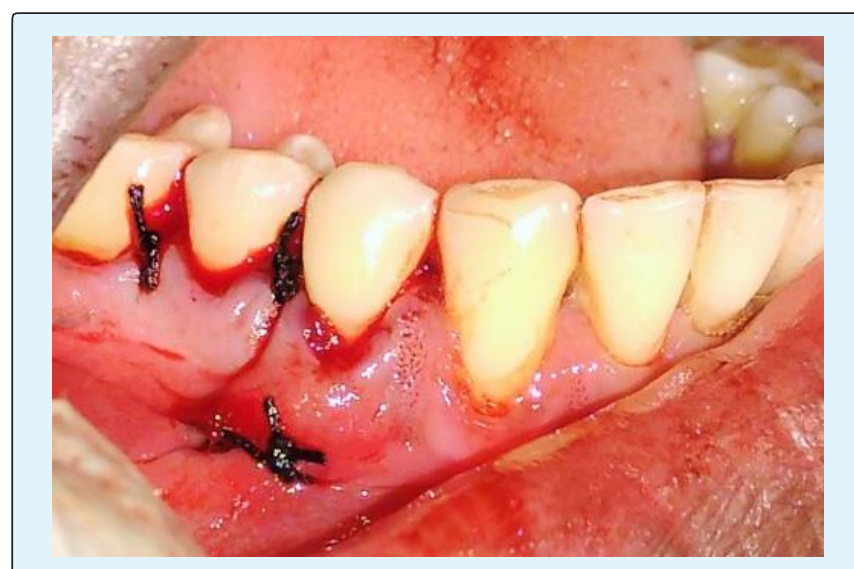

Figure 3: Intraoperative view after suturing.

Periodontal dressing was given for mandibular molars and patient was prescribed ibuprofen $400 \mathrm{mg}$ to be taken twice daily for 2-3 days to relieve pain. The sutures and dressing was removed after 1 week. Postoperatively the healing of the tissues at the site of frenotomy was uneventful and the gingival recession depth of mandibular right first molar reduced from 3-4 $\mathrm{mm}$ to $2-3$ $\mathrm{mm}$ (Figure 4). The pocket depth also reduced to $4 \mathrm{~mm}$ in relation to mandibular right molars and the patient was able to maintain adequate plaque control.

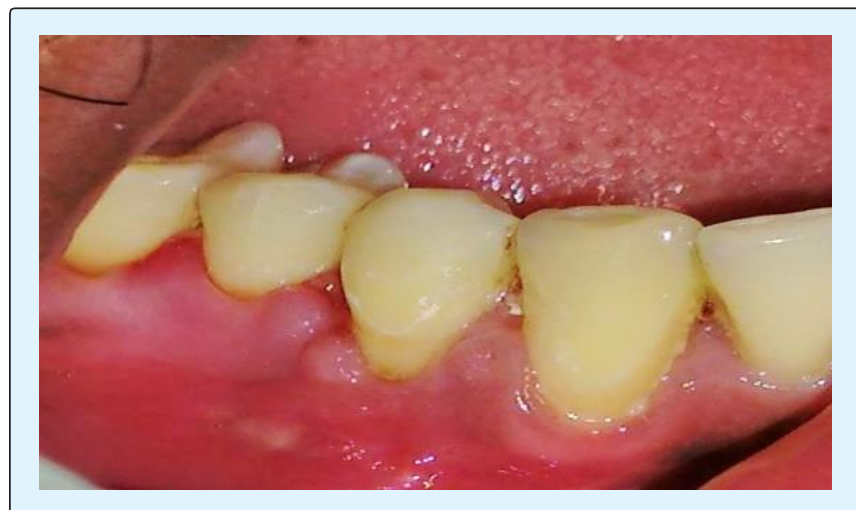

Figure 4: Postoperative view after follow up of 1 month.

\section{Discussion}

Aberrant frenal attachments are seen owing to the genetics of the individual or as a result of gingival recession reaching the frenal attachment. The papillary or papilla penetrating frenum are usually considered aberrant frenal attachments as they are present in close proximity to the gingival margin or are able to create tension which pulls the gingiva away from its position. 


\section{Open Access Journal of Dental Sciences}

This may interfere with plaque control, aesthetics and may cause gingival recession or mucogingival deformities $[1,2]$. In case adequate keratinised attached gingiva is present coronal to the frenum, it may not be considered aberrant. Inability to correct aberrant frenal attachment can result in diastema, gingival recession, gingivitis and periodontitis due to accumulation of food debris [1]. Majority of the aberrant frenal attachments requiring treatment include the labial frenii followed by lingual frenum in case it causes ankyloglossia or tongue tie. In handful of cases, buccal frenum poses as aberrant frenal attachments. In the present case the buccal frenum in relation to mandibular right first premolar gave a positive tension test and was thought to have caused gingival recession in mandibular right first premolar. Due to this, frenotomy of mandibular right first premolar was planned to prevent further recession and loss of supporting tissue which would exacerbate the already existing dentinal hypersensitivity and predispose to cervical or root caries. Frenotomy was preferred to frenectomy as the former is less traumatic. Although laser and electrocautery could be used for frenotomy [6,7] surgical frenotomy was planned in this case to avoid use of extra armamentarium and cost as the procedure was already clubbed with open flap debridement. Limitation of this case includes a short follow up time.

\section{Conclusion}

The gingival recession depth decreased postoperatively by $1 \mathrm{~mm}$ and healing was uneventful. Mandibular buccal frenotomy can prevent future gingival recession or other mucogingival deformities which can aid in maintaining adequate plaque control and aesthetics. Since it's a minor surgical procedure if required, can be clubbed with other surgical procedures to reduce the number of appointments and reduce patient cost and burden.

\section{References}

1. Newman MG, Takei HH, Klokkevold PR, Carranza FA (2012) Carranza's Clinical Periodontology. 11 $1^{\text {th }}(\mathrm{edn})$, Philadelphia: Elsevier Saunders, Missouri, pp: 595600 .

2. Cohen ES (2007) Atlas of Cosmetic and Reconstructive Periodontal Surgery. $3^{\text {rd }}$ (edn), BC Decker Inc.Hamilton, Ontario pp: 83-86.

3. Placek M, Miroslavs, Mrklas L (1974) Significance of the labial frenal attachment in the periodontal disease in man. Part 1 Classification and epidemiology of the labial frenum attachment. J Periodontol 45(12): 891894.

4. Silva CM, Ramos MM, Dalben GS (2008) Oral characteristics of newborns. J Dent Child (Chic) 75(1): 4-6.

5. Miller PD (1985) A classification of marginal tissue recession. Int J Periodontics Restorative Dent 5(2): 813.

6. Hungund $\mathrm{S}$, Dodani $\mathrm{K}$, Kambalyal $\mathrm{P}$, Kambalyal $\mathrm{P}$ (2013) Comparative Results of Frenectomy by Three Surgical Techniques-Conventional, Unilateral Displaced Pedicle Flap and Bilateral Displaced Pedicle Flap. Dentistry. 4: 183.

7. Khan NS, Abdul N, Iqbal SP (2014) Maxillary labial frenectomy using diode laser- report of two cases. International Journal of Oral Care and research 2(4): 94-97.

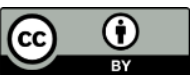

